\title{
An evaluation of the impact of shot and receiver lines spacing on seismic data quality - the Wierzbica 3D AGH seismic experiment
}

\author{
Jan Barmuta ${ }^{1}$, Monika Korbecka ${ }^{2}$, Piotr Hadro ${ }^{3}$, Krzysztof Pieniądz ${ }^{4}$, \\ Michał Stefaniuk ${ }^{5}$, Krzysztof Dzwinel ${ }^{6}$, Arkadiusz Buniak ${ }^{7}$ \\ ${ }^{1}$ AGH University of Science and Technology, Faculty of Geology, Geophysics and Environmental Protection; \\ al. A. Mickiewicza 30, 30-059 Krakow, Poland; e-mail: jbarmuta@agh.edu.pl (corresponding author); \\ ORCID ID: 0000-0002-8711-7978 \\ ${ }^{2}$ AGH University of Science and Technology, Faculty of Geology, Geophysics and Environmental Protection; \\ e-mail:mk.korbecka@gmail.com (former student) \\ ${ }^{3}$ AGH University of Science and Technology, Faculty of Geology, Geophysics and Environmental Protection; \\ e-mail:hadro@agh.edu.pl \\ ${ }^{4}$ AGH University of Science and Technology, Faculty of Geology, Geophysics and Environmental Protection; \\ e-mail:pieniadz@agh.edu.pl \\ ${ }^{5}$ AGH University of Science and Technology, Faculty of Geology, Geophysics and Environmental Protection; \\ e-mail: stefan@geolog.geol.agh.edu.pl; ORCID ID: 0000-0003-4442-9290, \\ ${ }^{6}$ Orlen Upstream, ul. Bielańska 12, 00-085 Warsaw, Poland; e-mail: krzysztof.dzwinel@orlen.pl \\ ${ }^{7}$ Orlen Upstream, ul. Bielańska 12,00-085 Warsaw, Poland; e-mail: arkadiusz.buniak@orlen.pl
}

(c) 2020 Authors. This is an open access publication, which can be used, distributed and reproduced in any medium according to the Creative Commons CC-BY 4.0 License requiring that the original work has been properly cited.

Received: 20 January 2020; accepted: 8 June 2020; first published online: 31 August 2020

\begin{abstract}
An attempt was made to describe the quality of the stacked seismic data semi-quantitatively with respect to the spacing of shot and receiver lines. The methods used included: signal-to-noise ratio calculation, seismic-to-well tie accuracy, wavelet extraction effectiveness and reliability of semi-automated interpretation of seismic attributes. This study was focused on the Ordovician-Silurian interval of the Lublin Basin, Poland, as it was considered as a main target for the exploration of unconventional hydrocarbon deposits. Our results reconfirm the obvious dependency between the density of the acquisition parameters and data quality. However, we also discovered that the seismic data quality is less affected by the shot line spacing than by comparable receiver line spacing. We attributed this issue to the fact of the higher irregularity of the shot points than receiver points, imposed by the terrain accessibility. We have also proven that the regularity of receiver and shot point distribution is crucial for the reliable interpretation of structural seismic attributes, since these were found to be highly sensitive to the acquisition geometry.
\end{abstract}

Keywords: seismic data interpretation, signal-to-noise ratio, seismic attributes

\section{INTRODUCTION}

Designing 3D seismic surveys is a challenging and often crucial task, one of key importance for exploration success and numerous good practices have been elaborated since 3D seismic surveys were brought into general use (e.g. Cordsen et al. 2000, Chaouch \& Mari 2006). However, unconventional reservoirs often require especially detailed and accurate seismic imaging. Reducing the spacing between the receivers and shot points is the current trend in seismic data acquisition 
projects (e.g.: Meunier \& Bianchi 2005, Meunier et al. 2008, Seeni et al. 2010, Ourabah et al. 2015). Smaller spacing between the receiver and shot lines results in a higher fold number, better signal-to-noise ratio (SNR), and lower bin size, which significantly reduces the uncertainty of the seismic imaging, and allows for the identification of subtle geological features (e.g.: Fusen et al. 2014, Xiao et al. 2014, Wang 2015). This practice, however, leads to a drastic increase in the costs of seismic surveys. As the economic aspect of seismic data acquisition plays an important role, it is vital to find a balance between the costs of seismic surveys and data quality, and to better understand the impact of acquisition geometry on interpretation.

In the case of onshore seismic surveys, the regularity of the location of shot and receiver points is another important factor controlling the seismic data quality. In highly urbanized areas, the planned regular distribution of both source points and receivers is often distorted due to land accessibility. Also, natural obstacles like swamps, marshes or natural preservation areas have a strong impact on the final survey geometry.

Usually, due to the receivers' easier handling and negligible impact on the natural environment, their locations are more regular and closer to the planned geometry. On the other hand, because of potential damage to the natural environment or infrastructure, the location of shot points is often determined by the above mentioned factors.

To date, seismic imaging of the Ordovician-Lower Silurian shale complex in Poland, considered as an unconventional reservoir, has given poor results, mainly due to the low acoustic impedance contrasts within the Silurian interval as well as an inadequate design of seismic surveys. The experimental Wierzbica 3D AGH seismic survey was carried out to test the ability of the seismic method to image the intra Silurian stratification and subtle structural features, such as small-scale faults or fractures, as well as to quantify the impact of acquisition parameters on seismic data quality.

This paper presents the results of the evaluation of the impact of shot and receiver line spacing on the data quality based on: signal-to-noise ratio (SNR), effectiveness of the wavelet extraction procedure, seismic-to-well tie accuracy and reliability of seismic attributes interpretation.

\section{GEOLOGICAL SETTINGS}

The research area is located at the southeastern termination of the Kock Fault Zone (KFZ), which is one of the most prominent fault zones in this part of the East European Craton (EEC) (e.g.: Narkiewicz 2010, Krzywiec et al. 2017, Kufrasa et al. 2018) (Fig. 1). The seismic survey adjoins the KFZ from the east. Recent geological and geophysical investigations allowed for the reinterpretation of the structure and evolution of the Lublin Basin and the KFZ. Based on these results, it was concluded that the KFZ should be regarded as a distal effect of the Variscan compressional thin-skin tectonics developed above the basement step, related to steep basement-rooted reverse faults that acted as a structural buttress (Krzywiec 2009, Krzywiec et al. 2017, Tomaszczyk \& Jarosiński 2017, Kufrasa et al. 2018).

The Wierzbica 3D AGH seismic survey was carried out in a structurally uncomplicated area. The structural style in the area of the Wierzbica 3D survey exhibits an almost flat layered model, with the Lower Palaeozoic strata dipping gently to the WSW at approximately $2^{\circ}$, while the Carboniferous and younger strata lie almost horizontally.

The stratigraphic profile in the study area starts from the Upper Proterozoic to the middle Cambrian (roughly corresponding to the Miaolingian series) coarse grained clastic deposits intercalated with basaltic lavas related to the break-up of the Pannotia supercontinent (Poprawa 2006, Golonka 2009). Above them, a continuous Ordovician-Silurian succession, reaching up to $1000 \mathrm{~m}$ in thickness and represented mainly by shales with limestone intercalations within the Ordovician interval, is present. An increased TOC content is recorded in the Ordovician and Lower Silurian shales; therefore, this interval was considered as a target of exploration for unconventional hydrocarbons (e.g. Porębski et al. 2013). The Silurian shales are covered by the Lower Devonian terrigenous sediments. The top of the Devonian appears as a distinct erosional surface, above which the uppermost Lower Carboniferous to Upper Carboniferous shallow marine and fluvial sequence is present (Waksmundzka 2010). The Mesozoic complex is represented by the Upper Jurassic and uppermost Lower Cretaceous to Upper Cretaceous sediments (e.g. Hakenberg \& Świdrowska 2001). Patches of thin Quaternary sediments formed during recent glacial periods are present at the surface. 


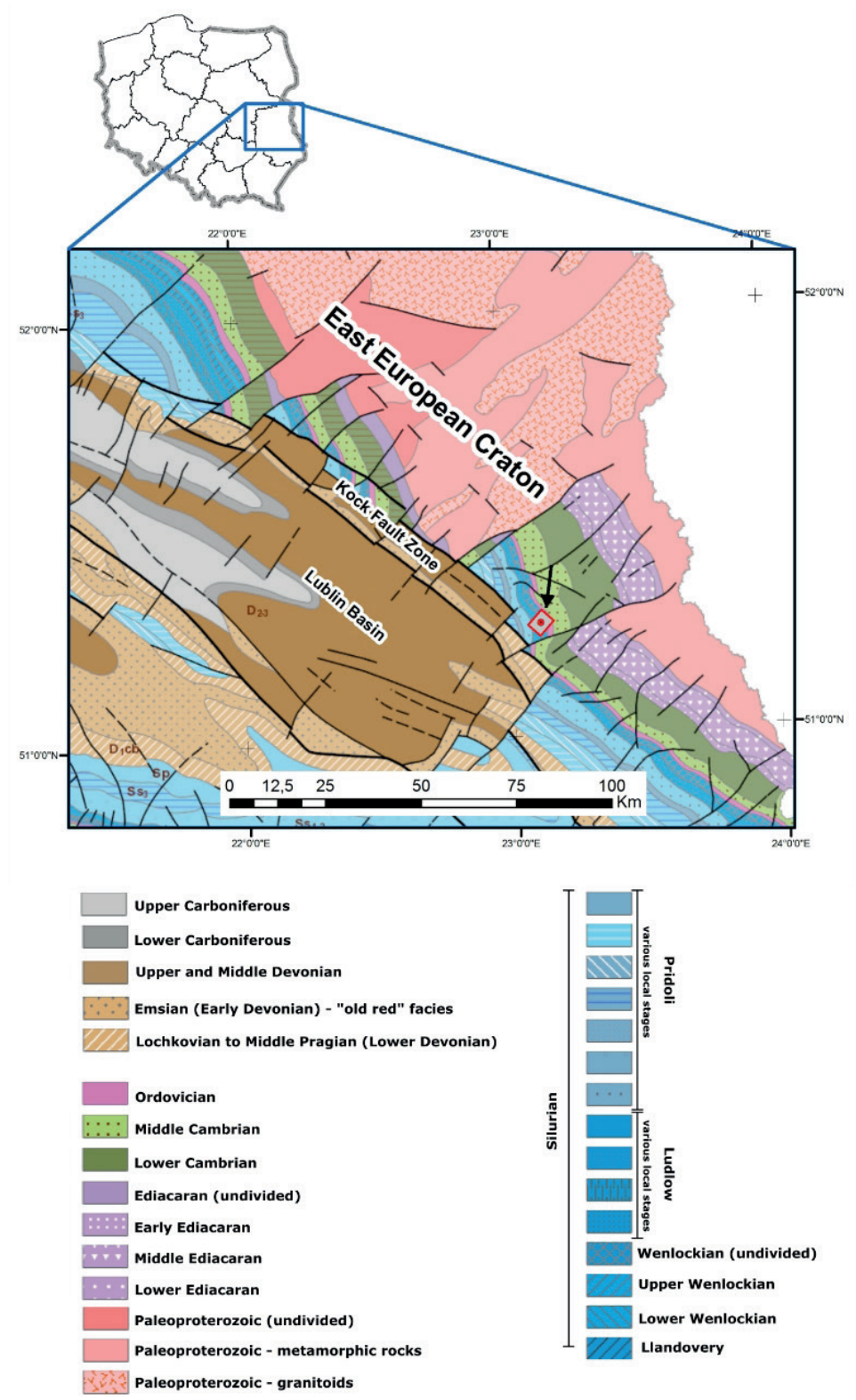

Fig. 1. Fragment of the geological map of horizontal cutting at $3000 \mathrm{~m}$ b.s.l. (after Kotański \& Buła 1997 with minor changes). The black arrow shows the location of the Wierzbica 3D AGH seismic survey and the Streczyn-OU1 well

\section{DATA}

\section{Seismic data}

The basic acquisition scheme of the Wierzbica 3D AGH seismic survey envisaged a $120 \mathrm{~m}$ spacing between the shot and receiver lines, while the shot and the receiver point spacing were $20 \mathrm{~m}$ and $40 \mathrm{~m}$, respectively (Fig. 2A). Each receiver point consisted of 12 geophones arranged in two lines 3 meters apart, and with $1.2 \mathrm{~m}$ spacing between individual geophones. For each shot point, a group of four vibrators (AHV IV) were used.
A linear, 12 second long sweep was used with start and stop frequency equal $6 \mathrm{~Hz}$ and $80 \mathrm{~Hz}$, respectively. A minimum recorded offset was 13 meters, while the maximum offset equals 6604 meters. Due to the terrain conditions (i.e. swamps, marshes, settlements, etc.) the final acquisition pattern differed from the design, mainly in terms of shot point location (Fig. 2B). During the processing phase, selected shot and receiver points, or entire shot and receiver lines, were eliminated to simulate various acquisition patterns. As a result, 21 different cubes of seismic data were produced. 
All versions of the acquired seismic data were processed using an identical workflow (Fig. 3), with identical bin size equals $20 \mathrm{~m} \times 20 \mathrm{~m}$.

The aim of the workflow was not only to image the subsurface of the research area but also to preserve real amplitude relationships. Thus the surface consistent procedures were applied and coherent noise, like ground roll wave, refraction and multiples, was removed before the deconvolution procedure.
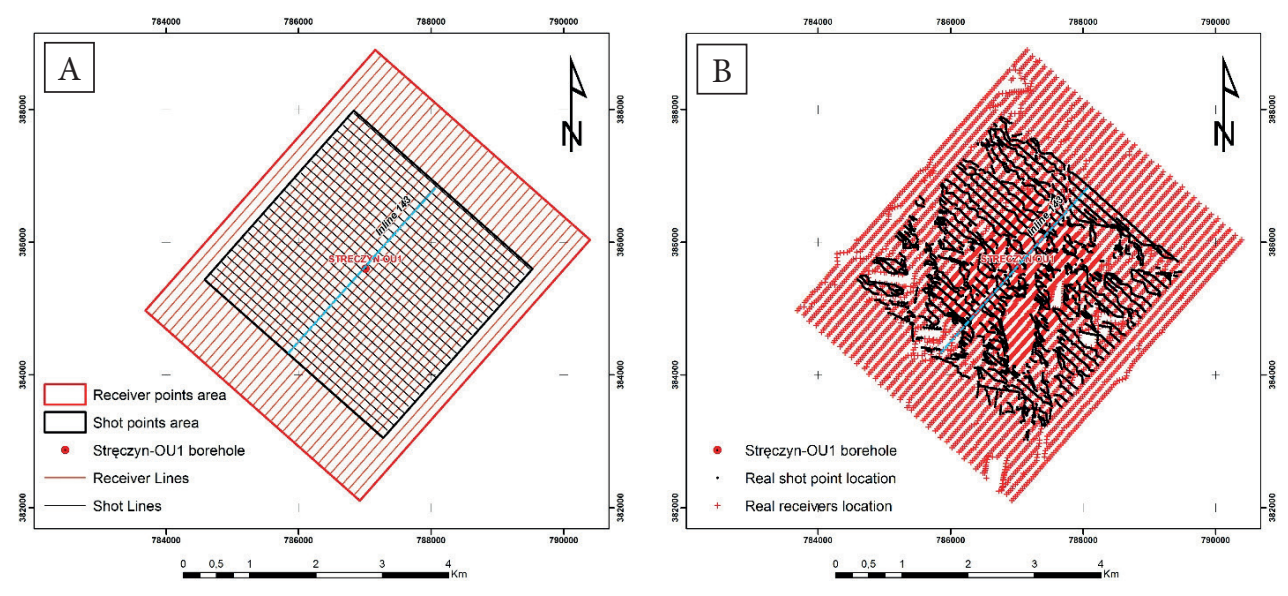

Fig. 2. Planned acquisition scheme for the Wierzbica 3D AGH seismic survey (A). Final field acquisition scheme for the Wierzbica $3 D A G H(B)$. The blue line on both maps $(A, B)$ shows the position of the Inline 143 presented in subsequent figures

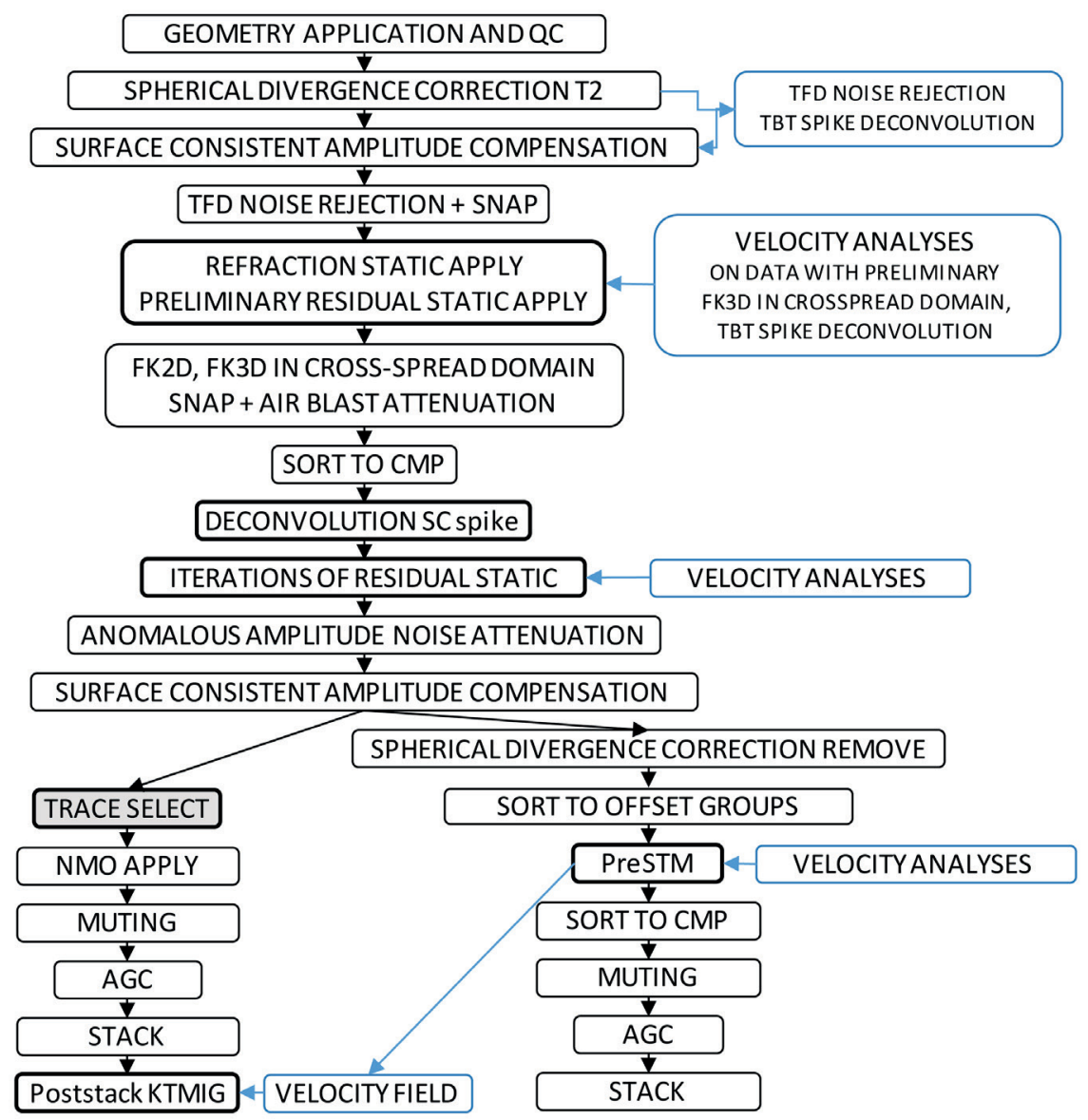

Fig. 3. Scheme of the processing workflow 
After the initial processing steps and denoising, data was sorted into offset groups and then pre-stack time migrated (PreSTM). During the pre-stack time migration, the velocity field was repeatedly updated to obtain the most accurate velocity model. The final velocity model was then used as an input for the post-stack migration (PostSTM) procedure (Fig. 3).

To test the influence of shot and receiver lines spacing on the seismic data quality, seven cubes were selected from the available 21 versions of seismic data, and organized in a matrix (Tab. 1). For cubes 1, 2 and 3 located along the diagonal of the matrix, the shot and receiver line spacing increases proportionally, which results in a squareshape box. While the pairs of cubes $12 \mathrm{~A}-12$ and 5-6 exhibit the same box size, they differ in the spacing of the shot and receiver lines. For example, for cube $12 \mathrm{~A}$, the shot and receiver lines intervals equal 120 and 240 meters, respectively, while for its counterpart, cube 12 , the intervals are 240 and $120 \mathrm{~m}$. Based on the analysis of these pairs, the anticipated equivalence of shot and receiver lines was investigated.

Table 1

Basic acquisition parameters for tested cubes of the Wierzbica $3 D$ AGH seismic survey. Bin size equals $20 \times 20$ meters for all versions of seismic data

\begin{tabular}{|c|c|c|c|c|}
\hline & \multicolumn{3}{|c|}{ Shot line spacing $[\mathrm{m}]$} \\
\hline & & 120 & 240 & 360 \\
\hline \multirow{3}{*}{ 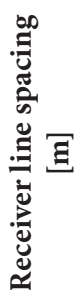 } & בิత్ & Cube 1 & Cube 12 & Cube 6 \\
\hline & $\stackrel{\circ}{\text { ㄱ }}$ & Cube 12A & Cube 2 & - \\
\hline & : & Cube 5 & - & Cube 3 \\
\hline
\end{tabular}

The deterioration of seismic data quality related to the spacing of lines is clearly visible on cubes located along the diagonal of the matrix, i.e. cubes 1,2 and 3 (Tab. 1, Fig. 4). It mainly affects the continuity of the intra Silurian horizons and causes the overall blurring of seismic image. However, for pairs $12-12 \mathrm{~A}$ and $6-5$ the visual evaluation is insufficient to determine the cube of higher quality (Fig. 5).
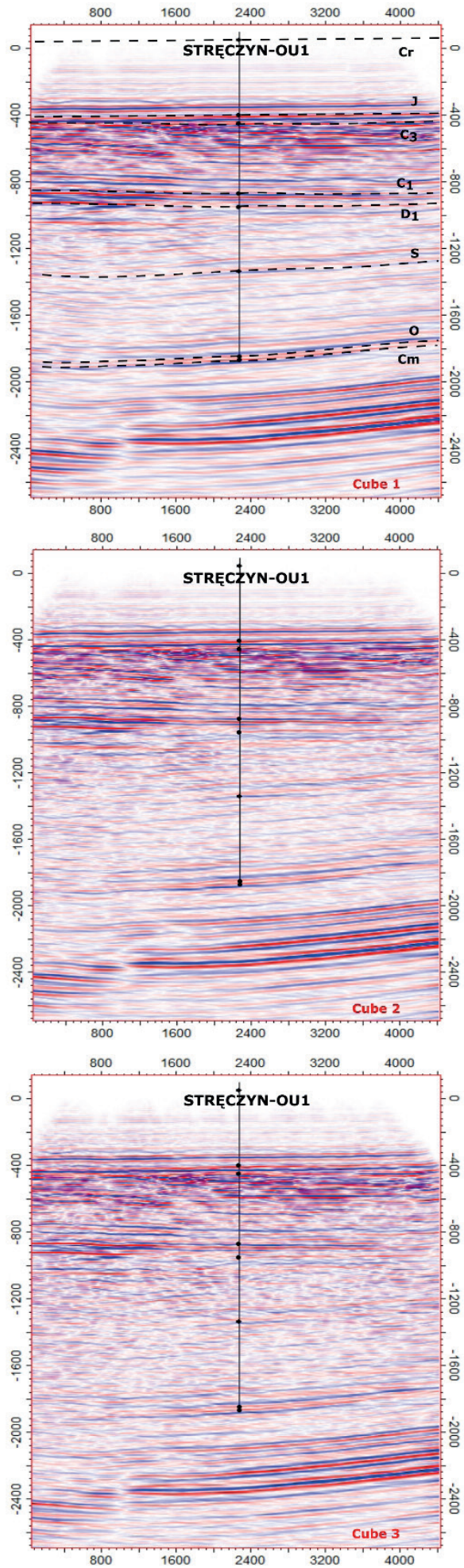

Fig. 4. Examples of the inline no. 143 for cubes 1, 2 and 3 with the position of the Streczyn-OU1 well and main stratigraphic horizons drawn on cube 1 . The seismic sections are in the time domain (TWT, ms). Note the increasing obscurity of the seismic horizons within the Silurian interval for cubes 2 and 3. Cr - Cretaceous, J - Jurassic, C3 - Upper Carboniferous, C1 - Lower Carboniferous, D1 - Lower Devonian, S - Silurian, $\mathrm{O}$ - Ordovician, Cm - Cambrian 

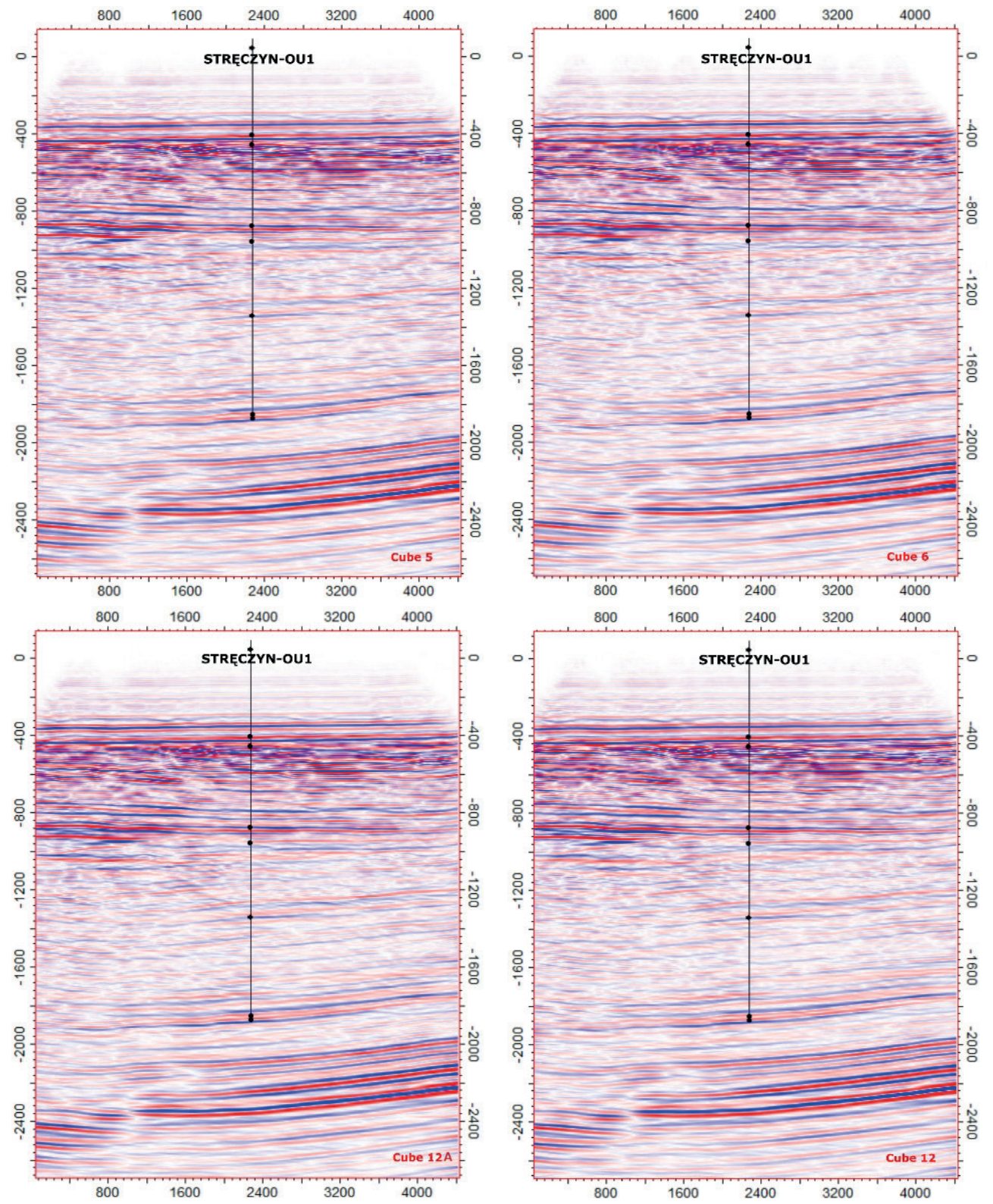

Fig. 5. Inline 143 for cubes 5, 6, 12A and 12. Note the almost no visible differences between 5 v 6 and $12 \mathrm{~A}$ vs 12 cubes

\section{Borehole data}

The Stręczyn-OU1 well (3500 MD) was drilled in the center of the Wierzbica 3D AGH seismic survey (Fig. 2). It reached the Cambrian sandstones directly below the thin Ordovician complex (Fig. 6). For the purpose of this study, a basic set of well logs, stratigraphic tops, check shot and well deviation data necessary for a reliable seismic-towell tie procedure was provided (Tab. 2).

The acoustic impedance (AI) and reflection coefficients (RC) were calculated using the transient time (DT) and density (RHOB) curves. The
Cretaceous interval, represented mainly by chalk, marls and limestones, generally exhibits low AI contrasts. However, large RC values are observed in the lowermost part of the Cretaceous, as well as in the Jurassic interval. The Carboniferous complex, composed mainly of sandstones, mudstones with subordinate coal and limestone layers, is also characterized by large RC values. The Silurian-Lower Devonian interval shows low AI contrasts related to the monotonous shale sequence, while the presence of thin limestone intercalations within the Ordovician interval resulted in large AI contrasts. 


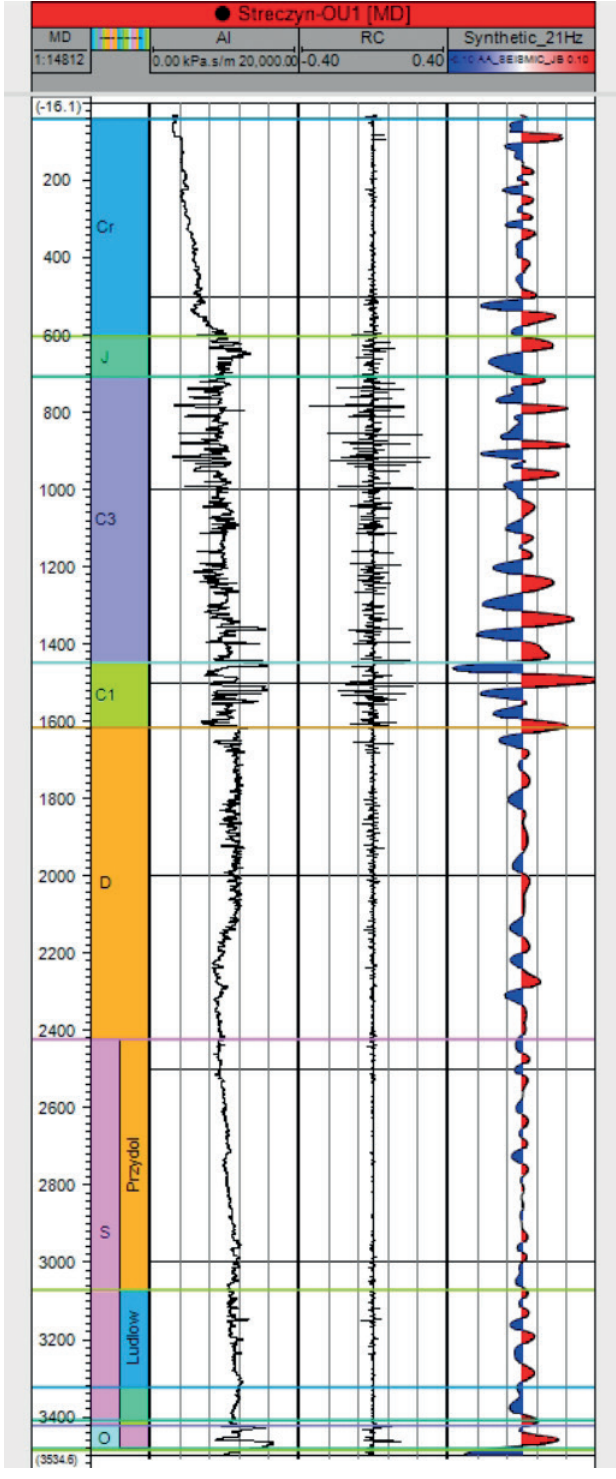

Fig. 6. AI and RC logs with a synthetic seismogram created using the $21 \mathrm{~Hz}$ Ricker wavelet. The RC track is scaled from -0.40 to 0.40 . Note, there are no significant reflections within the Silurian interval

Table 2

Stratigraphic tops for Stręczyn-OU1 well. Negative TWT value for the Cretaceous result from the applied seismic reference datum

\begin{tabular}{|l|c|c|}
\hline \multicolumn{1}{|c|}{ Stratigraphy } & MD [m] & TWT [ms] \\
\hline Cr & 40.00 & -47.05 \\
\hline J & 603.00 & 405.70 \\
\hline C3 & 707.50 & 456.93 \\
\hline C1 & 1447.00 & 876.87 \\
\hline D & 1615.00 & 959.40 \\
\hline S & 2422.00 & 1342.73 \\
\hline O & 3421.85 & 1855.59 \\
\hline Cm & 3467.00 & 1876.74 \\
\hline
\end{tabular}

\section{METHODS}

The quality of seismic data was evaluated using the four methods described below. Cube 1, characterized by the highest shot and receiver line density, was regarded as a benchmark for all other cubes.

Using SNR estimation by means of the multi-coherence method (White 1973), for each version of seismic data the SNR was calculated within the 1500-2500 ms time gate. The multi-coherence method defines the signal of a seismic record as a component which correlates from trace to trace, while noise is considered a non-correlatable part. The multi-coherence method is thus only able to determine the incoherent noise. It was assumed that coherent noise, like multiples, had been eliminated during the processing phase by using such procedures like 3D F-K filtering in cross-spread domain and by accurate velocity analysis. The results of the SNR estimations are presented as a set of maps and histograms (Figs. 7, 8).

The synthetic seismogram for the Stręczyn-OU1 well was calculated using the available borehole data and seismic cube 1 . The $21 \mathrm{~Hz}$ zero-phase Ricker wavelet, based on the cross-correlation criterion, was selected from the theoretical wavelets available in the Petrel software as the most relevant. The wavelet was then applied to all other versions of seismic-well-ties. The correlation value calculated for the Silurian interval (1340-1840 ms time gate), considered as the most sensitive to the noise level, was then used as an indicator of the seismic data quality (Figs. 9, 10).

The quality of the seismic data was also analyzed in terms of the effectiveness of the wavelet extraction procedure (Figs. 11, 12). Using the deterministic extraction method and the Extended White algorithm available in the Petrel software, a wavelet was extracted for each cube along the Stręczyn-OU1 well. The extraction was restricted to the Silurian interval (i.e. $1340-1840 \mathrm{~ms}$ ). As mentioned above, the Silurian interval exhibits low AI contrasts, so it was assumed that the quality ("noisiness") of the seismic data would significantly affect the accuracy of the wavelet extraction. The Ordovician strata were intentionally excluded from the extraction time gate, as the strong RCs observed in this part of the profile mitigated the effect of incoherent noise on the effectiveness of the wavelet extraction algorithm. 


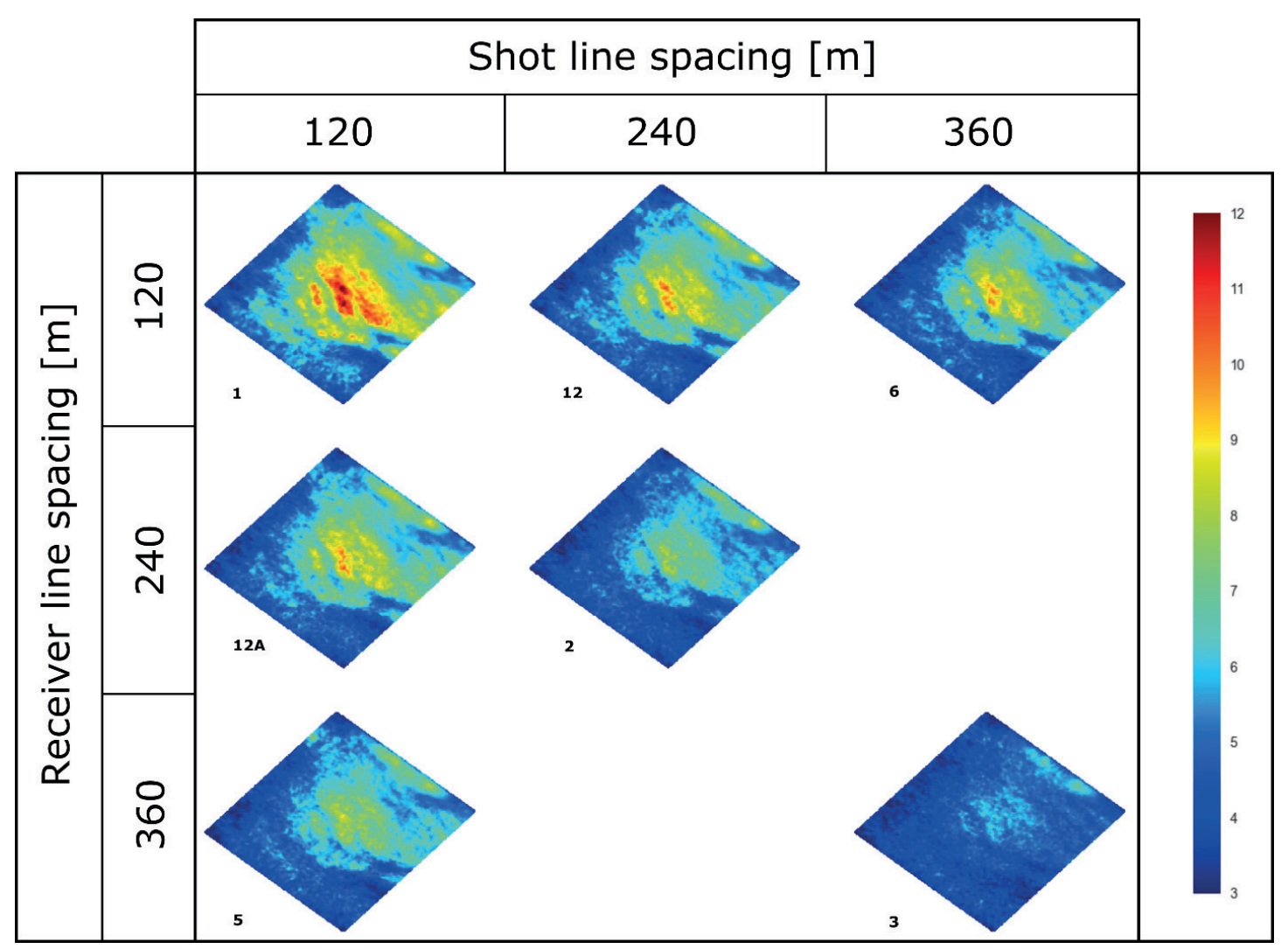

Fig. 7. SNR maps for all seven cubes. Note, there are no visible difference between test 12 and 12A. The test 6 exhibits higher SNR than test 5. Maps ordered as in Table 1

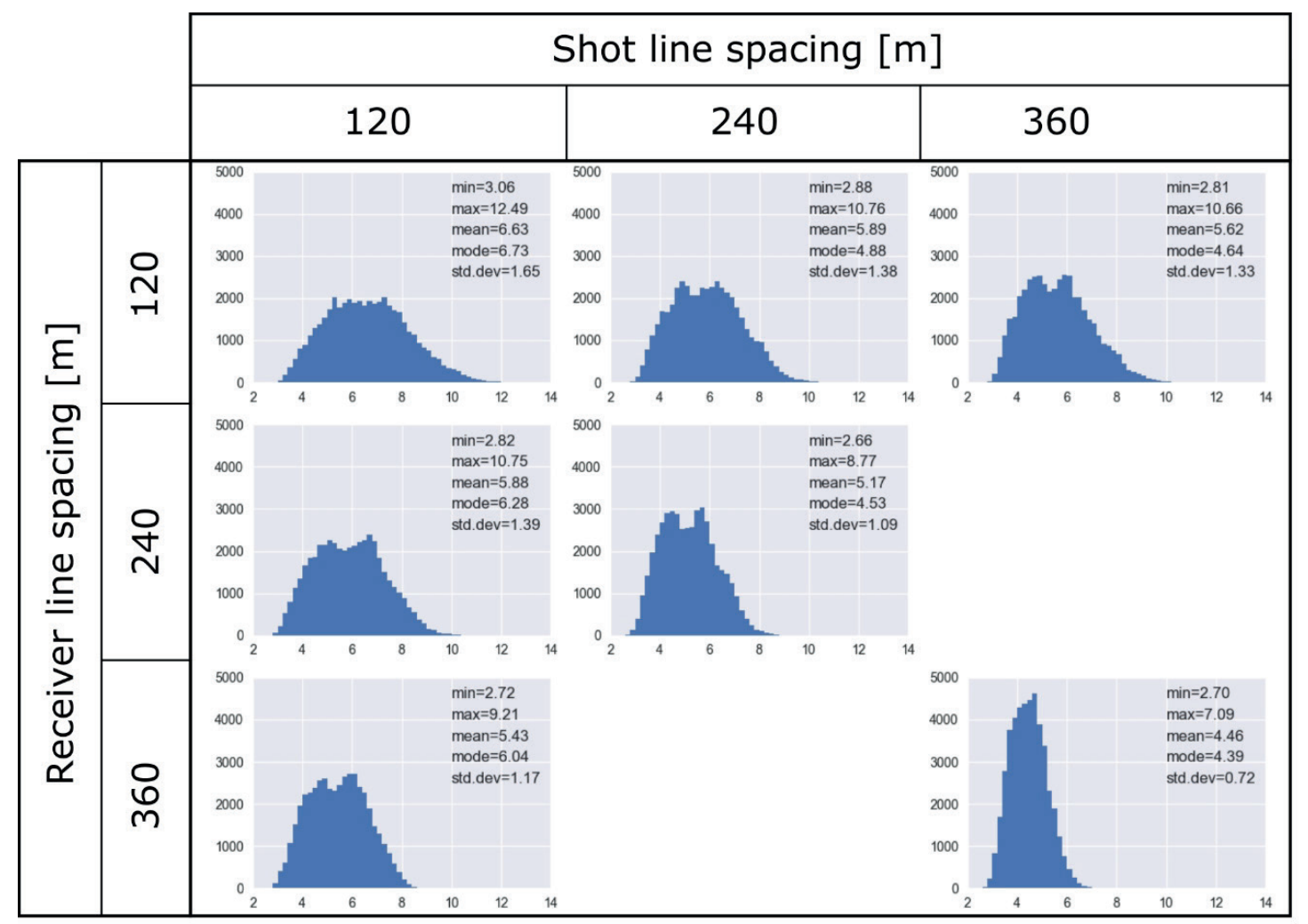

Fig. 8. SNR histograms and basic statistics for each version of the seismic data 


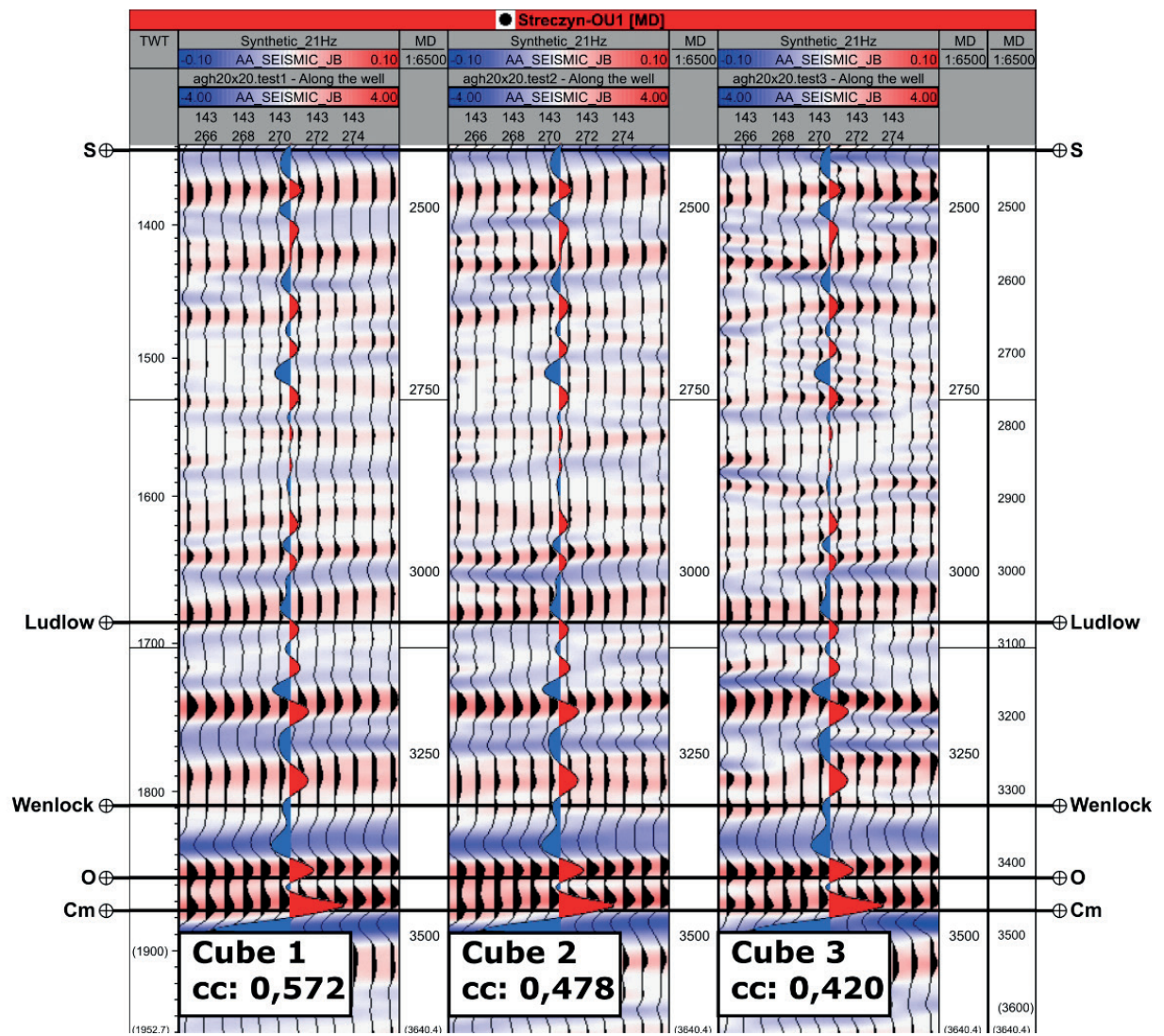

Fig. 9. Synthetic seismograms for cubes 1, 2 and 3 supplemented with the cross-correlation value (cc)

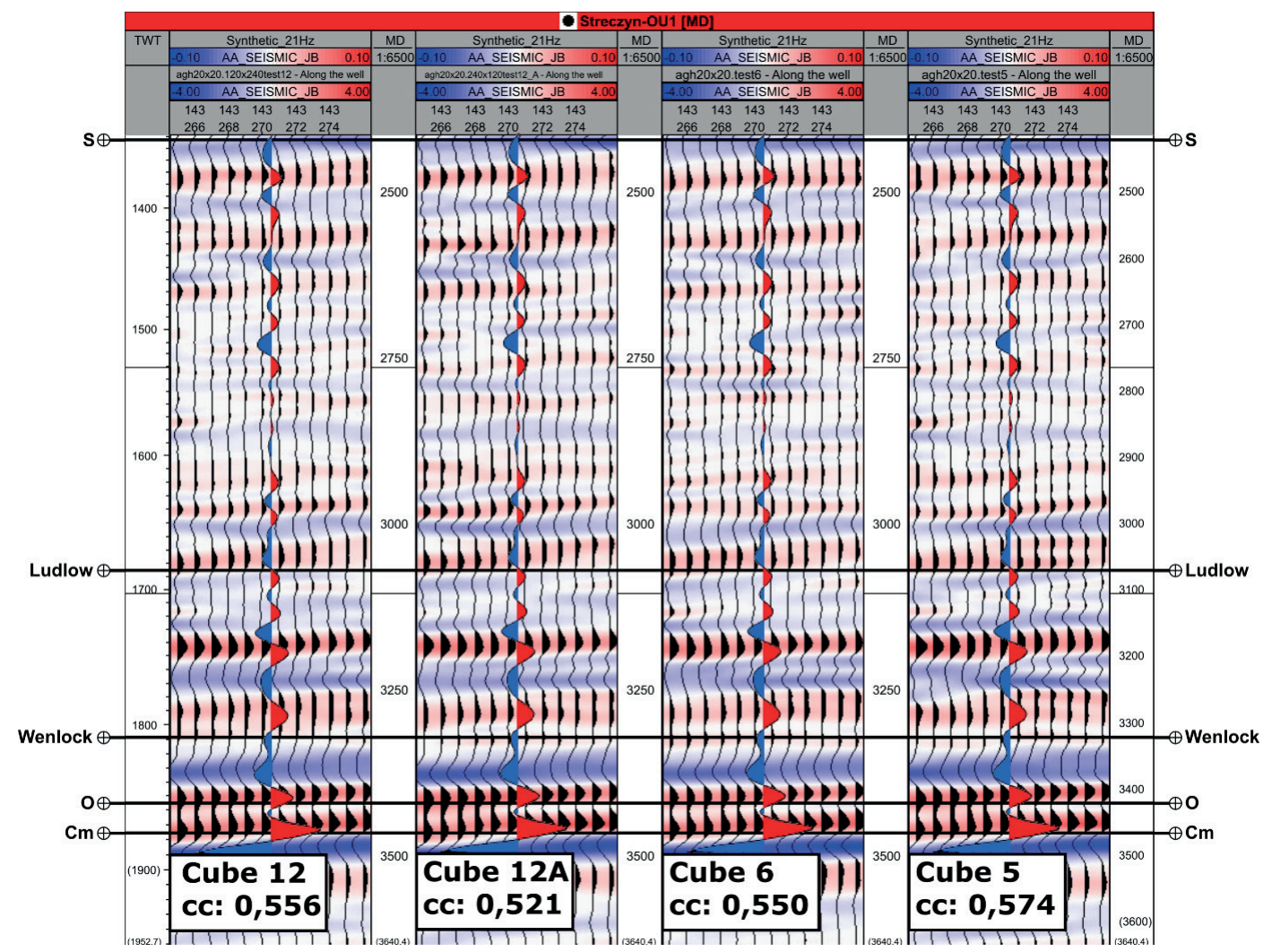

Fig. 10. Synthetic seismograms for cubes 5,6 and 12, $12 \mathrm{~A}$ supplemented with the correlation value (cc) 


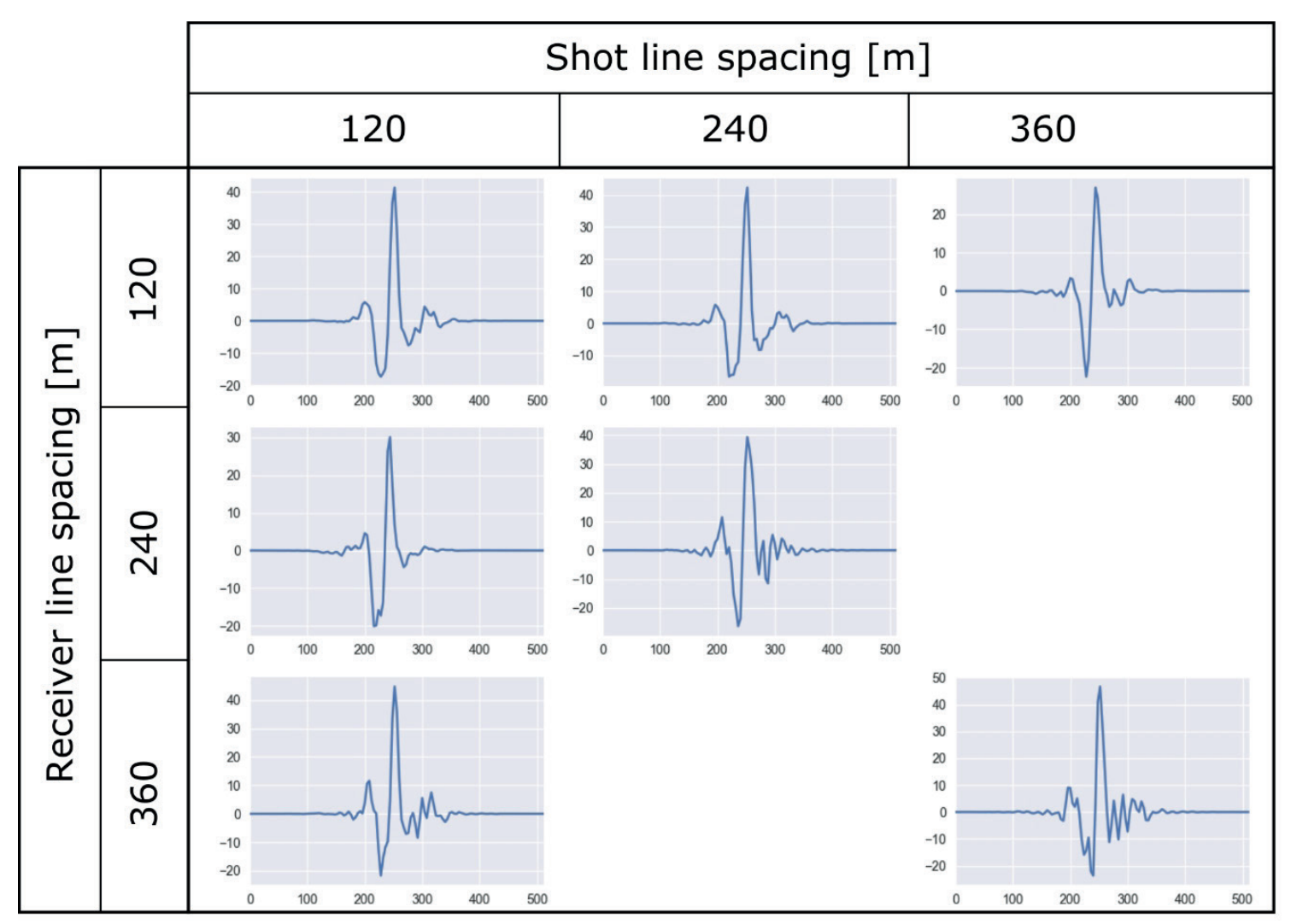

Fig. 11. Results of the wavelet extraction procedure

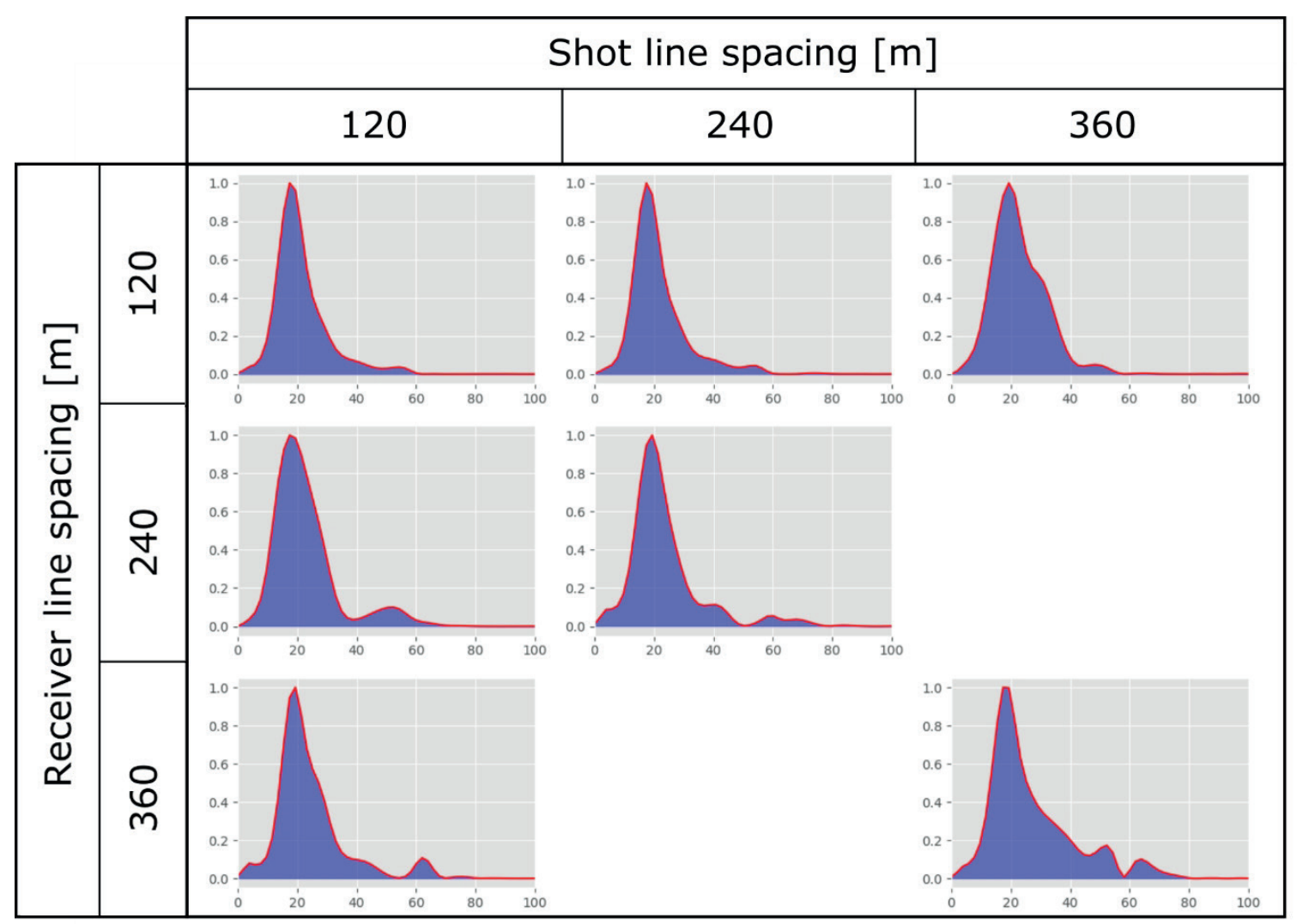

Fig. 12. Frequency spectrum of the extracted wavelets 
Using the workflow elaborated previously by Barmuta et al. (2017) and fixed for all cube parameters, an Ant Track seismic attribute (Pedersen et al. 2002) was calculated and automatic fault extraction was applied for each cube (Fig. 13). In order to obtain optimal results, the seismic data was preconditioned using the OpendTect implementation of structure-orientated filters (SOF) (the Dip Steering Plugin). Then, the fault enhancement procedure (OpendTect's Fault Enhancement Filter - FEF) was applied. The FEF is an "edge preserving" filter, which removes incoherent noise from the seismic data and preserves the sharp edges along fault zones. The noise-free and sharp edge versions of all cubes were used as input for the similarity attribute calculation. Finally, using the similarity cubes as an input, the Ant Track attribute, designed for improving fault imaging on seismic data, was calculated. Because of the observed strong footprint, the directions corresponding to the inline and crossline azimuths were filtered out. The parameters for the structural filtering, fault enhancement, similarity and Ant Track attributes were optimized for cube 1, and then consistently used for all other cubes (Fig. 14).

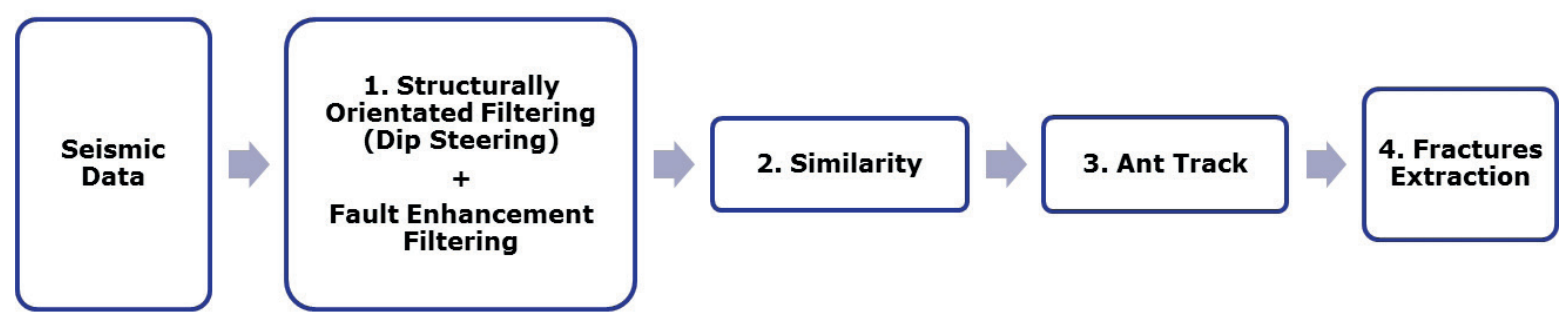

Fig. 13. Attribute calculation and fracture extraction workflow

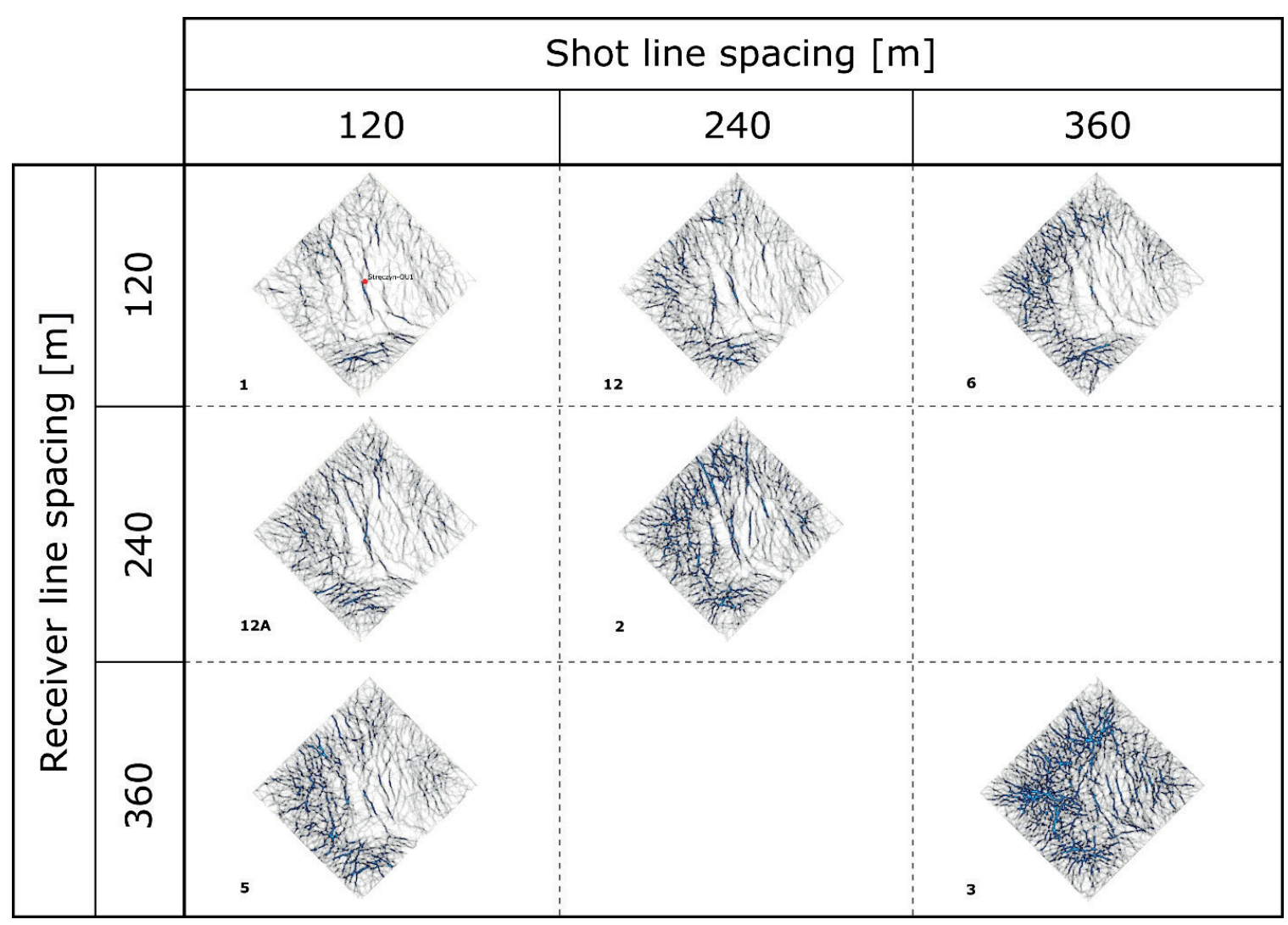

Fig. 14. The final Ant Track attribute. Time slice depth corresponds roughly with the top of the Ordovician 


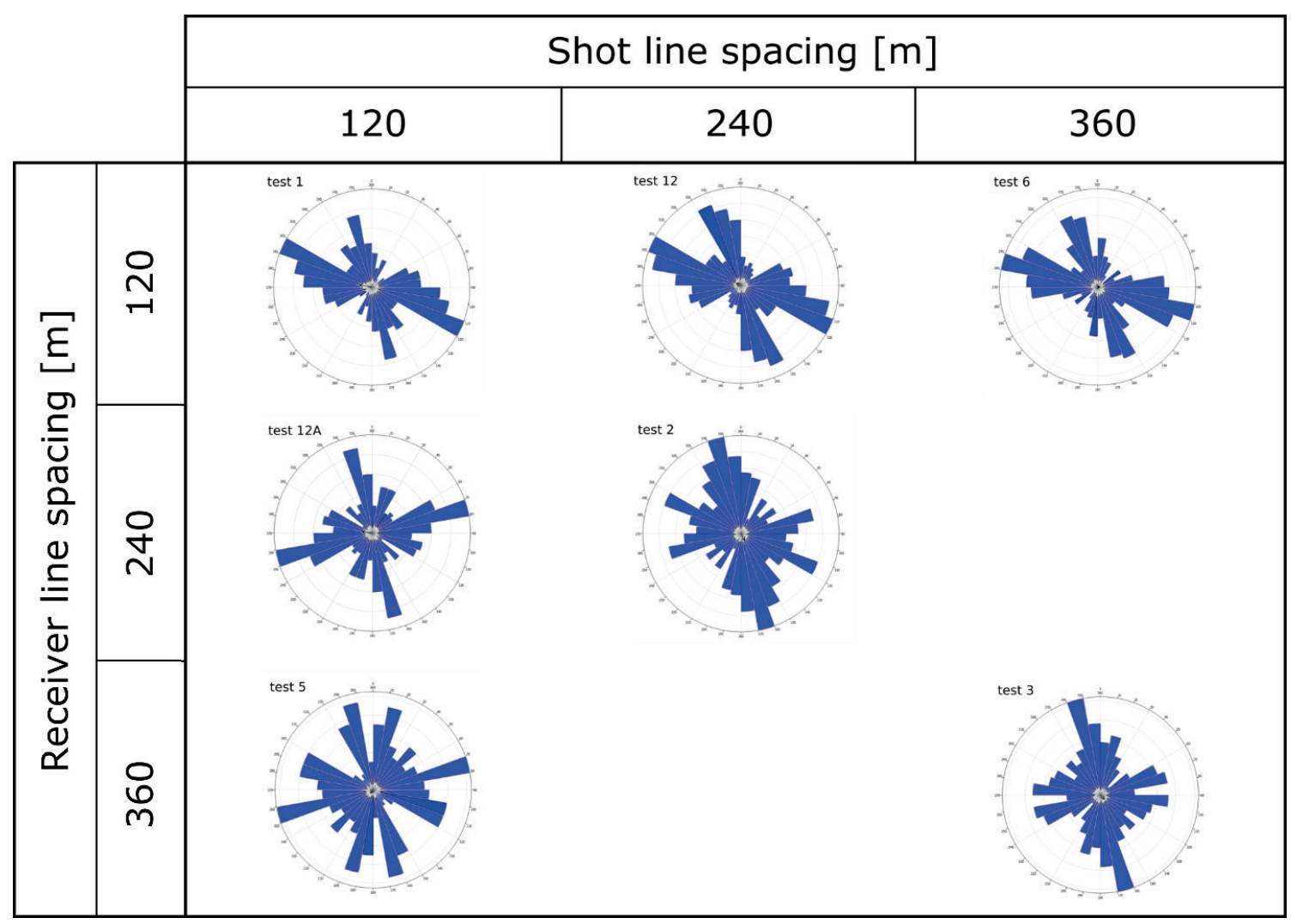

Fig. 15. Rose plots representing the fractures' plane strike for all seven versions of seismic data. Note the huge similarity for tests 1,12 and 6

The automatic fault extraction was run on all seven cubes. As in the previous steps, the parameters of the extraction procedure were attuned to cube 1 and then applied to all other versions of seismic data. The extraction was applied within the time gate corresponding to the Silurian-Ordovician interval. As a result, seven sets of fault patches were obtained. The fault patches were depth-converted using the time-depth model obtained during the seismic-to-well tie process.

The number of fault patches and their structural attributes, like dip and strike, were then analyzed and compared for each cube (Fig. 15).

\section{RESULTS}

\section{SNR maps and histograms}

The maps of the SNR illustrate the quality of the seismic data for all seven versions (Fig. 7). On all maps, the SNR ratio decreases from the center to the edges of the seismic survey, which is an effect directly linked to the fold number. Also, the linear zones of lower SNR correspond to the small-scale faults located in the center of the seismic survey. The gradual degradation of seismic data with relation to the larger box size can be inferred based on maps for cubes 1, 2 and 3 (Figs. 4, 7). Mean SNR values for these cubes are 6.63, 5.17 and 4.46, respectively (Fig. 8). Which implicates that the SNR for cube 2 decreases by $22 \%$ and by $32.7 \%$ for cube 3 . The histograms located along the diagonal of the matrix exhibit also gradually smaller spread (i.e. lower standard deviation values) with increasing shot lines and receiver lines spacing. On the other hand, SNR maps for cubes $12 \mathrm{~A}$ and 12 display no significant differences, while cube 6 shows slightly higher values compared to cube 5 (Figs. 7, 8). Small differences between cubes 12 and $12 \mathrm{~A}$ are also confirmed by the histograms' shapes and basic statistics, e.g. mean value equals 5.89 and 5,88 , (i.e. $~ 11,2 \%$ decrease comparing to cube 1 ), and max. value: 10.76 and 10.75, respectively. For cubes 5 and 6 , the differences are more significant and easily visible on the maps, as the SNR mean values reach 5.43 and 5.62 (indicating 18\% and $15.2 \%$ decrease in the SNR compared to cube 1). 
Cube 5 is not only characterized by a lower mean value, but also by a much lower standard deviation value (1.17 versus 1.33 ), which implies a general shift towards the lower values.

\section{Synthetic seismograms and results of the wavelet extraction procedure}

The correlation values for synthetic seismograms constructed using the theoretical Ricker wavelet indicate a general degradation of the seismic data together with the increase in shot and receiver line spacing (Figs. 9, 10). Noticeably, cube 12 exhibits a higher correlation value than its counterpart, cube 12A. Surprisingly, the correlation value for cube 5 is also slightly higher than for cube 1 ( 0.574 and 0.572 , respectively). Based on visual evaluation, it can be stated that for all cubes two high-amplitude seismic events corresponding to the top and bottom of the Ordovician correlate well for all cubes, while the seismic horizons within the upper part of the Silurian interval do not match the synthetic data.

The results of the wavelet extraction procedure show the influence of seismic data quality on the resultant wavelet. All the wavelets are no zero-phase (Fig. 11), however greater phase rotations are observed for cubes 2, 3, 6 and 5. The calculated wavelet's phase rotation for each cube (Tab. 3) indicates dispersed values. It is clearly visible that a larger box size results in a wider frequency spectrum and increased amplitude values for frequencies higher that $40 \mathrm{~Hz}$.

Table 3

Wavelets' phase rotation

\begin{tabular}{|c|c|c|c|c|}
\hline & \multicolumn{3}{|c|}{ Shot line spacing $[\mathrm{m}]$} \\
\hline & & 120 & 240 & 360 \\
\hline \multirow{3}{*}{ 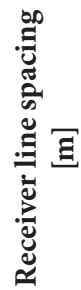 } & తి & -18.87 & -1.7 & -63.00 \\
\hline & $\stackrel{\text { ㄱ }}{\text { N }}$ & -57.62 & -70.24 & - \\
\hline & : & -27.00 & - & -49.84 \\
\hline
\end{tabular}

The frequency spectrum for the wavelet extracted from cube 1 (Fig. 12) reaches $60 \mathrm{~Hz}$, but frequencies higher than $35 \mathrm{~Hz}$ are of an insignificant magnitude. The wavelet central frequency is
$19 \mathrm{~Hz}$. The wavelet extracted from cube 12 is almost identical to the one extracted from cube 1. The wavelets derived from all other cubes are characterized by higher magnitudes of high frequencies (above $35 \mathrm{~Hz}$ ) and an increased frequency range. Also, the central frequencies for these cubes are slightly higher, reaching $20 \mathrm{~Hz}$. The correlation value between the synthetic seismogram obtained based on the extracted wavelets and seismic data (Tab. 4) generally decreases together with the increasing shot and receiver lines spacing. It is evidently well observed for the first row of the matrix, i.e. cubes 1,12 and 6 , as well as along the diagonal (cubes 1, 2, 3). The correlation value for cube $12 \mathrm{~A}$ is much lower than for cube 12 , while, surprisingly, cube 5 exhibits a much higher correlation than cube 6 .

\section{Table 4}

Correlation values for the synthetic seismograms using the extracted wavelets

\begin{tabular}{|c|c|c|c|c|}
\hline & \multicolumn{3}{|c|}{ Shot line spacing $[\mathrm{m}]$} \\
\hline & & 120 & 240 & 360 \\
\hline \multirow{3}{*}{ 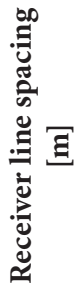 } & 공 & 0.629 & 0.588 & 0.522 \\
\hline & 욤 & 0.461 & 0.555 & - \\
\hline & i & 0.539 & - & 0.372 \\
\hline
\end{tabular}

\section{Detectability of small-scale faults}

The results of the semi-automated fault extraction procedure (Figs. 13, 14) show that the number of extracted faults increases along with shot and receiver line spacing (Tab. 5). This can be clearly observed on the timeslices for cubes 1,2 and 3 located along the diagonal of the matrix (Fig. 14). Timeslices for cubes 12 and 5, and their counterparts visually show an almost identical lineament pattern. The fracture extraction process summarized on the rose-plot diagrams (Fig. 15) allows for the conclusion to be drawn that the azimuth distribution is highly dependent on the acquisition pattern. The rose-plots for cubes 1 and 12 show a comparable distribution of fracture strikes, based on which two fracture sets can be distinguished. Surprisingly, even for highly rectangular box (i.e. cube 6) the two fracture sets are clearly visible. 
The strike azimuth of the first set is in a range of 340-350 degrees, while the azimuth of the second set is between 290-300 degrees. However, the first set of fractures $\left(340-350^{\circ}\right)$, often masked, is also observable on other rose-plots generated by the fracture extraction procedure. The highest dispersion of azimuths is noticed for cube 5 .

Table 5

Numbers of fracture patches extracted

\begin{tabular}{|c|c|c|c|c|}
\hline & \multicolumn{3}{|c|}{ Shot line spacing $[\mathrm{m}]$} \\
\hline & & 120 & 240 & 360 \\
\hline \multirow{3}{*}{ 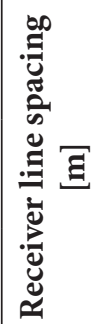 } & ঙ્తి & 155 & 211 & 180 \\
\hline & $\stackrel{\text { I }}{\text { N }}$ & 205 & 240 & - \\
\hline & : & 208 & - & 237 \\
\hline
\end{tabular}

\section{DISCUSSION}

The SNR maps and histograms suggest that the shot lines spacing affects the data quality less than the receiver lines spacing. In other words, cubes 12 and 6 are of a higher quality than their counterparts. Apparently, this effect is stronger for larger box size (compare pairs 5-6 and 12A-12 on Figures 7 and 8). Unexpectedly, the correlation values for cube 5 and synthetic seismograms, generated using both theoretical and extracted wavelets, are higher than for cube 6 , which exhibit a higher SNR. As we are currently unable to provide an explicit explanation of this issue, we suggest that this abnormally high value may have resulted from the designed time gate used for the calculation of a correlation coefficient or from the algorithm used for the correlation determination. However, this observation leads to the conclusion that the correlation coefficient shouldn't be considered as an ultimate indicator of the quality of seismic-to-well ties. Interpreting the results of the wavelet extraction procedure, it can be inferred that the increased width of the frequency spectrum is related to the incoherent noise present in the seismic data and should be treated as a negative effect. It was also noticed that, despite the visually similar results of the wavelet extraction procedure for cubes 1, 12 and 12A (Figs. 11, 12), the calculated phase rotation differs strongly (Tab. 3). We suppose that this effect is a result of a high-frequency incoherent noise which affects the phase calculation algorithm.

Summarizing the results from the SNR calculations, the reliability of the seismic-to-well tie process and the effectiveness of wavelet extraction, it can be stated that an obvious relationship between seismic data quality and box size is observed, and no significant changes in the SNR parameter related to the shot and receiver line swapping were observed.

On the other hand, the results of structural seismic attributes analysis are highly sensitive to the acquisition pattern and regularity (Figs. 2, $14,15)$. It is demonstrated that the number of detected fracture planes increase with the size of the box. What is more, based on the constructed roseplots, we have shown that the fracture pattern differs significantly with respect to the acquisition geometry. The most important observation can be made based on cubes 12 and 6 and their counterparts, i.e. cubes $12 \mathrm{~A}$ and 5 . Cubes $12 \mathrm{~A}$ and 5 produced erroneous results despite having the same box size. This effect proves the importance of the regularity in seismic acquisition surveys. Thus, it can be stated that the interpretation of small-scale faults and fractures based on the seismic attributes alone should be regarded as uncertain, unless supported by other methods or data (e.g. seismic anisotropy analysis, geomechanical modelling, borehole image logs). Our studies may explain the lack of an evident correlation between geomechanically modelled and seismic-derived fractures, which was first observed by Kufrasa et al. (2018).

\section{CONCLUSIONS}

To conclude, the Wierzbica 3D AGH experimental seismic survey was designed to test the influence of acquisition parameters on the seismic data quality. In this paper we presented selected tests regarding the evaluation of stacked and migrated seismic data based on the four methods described above. Besides the obvious result, showing the high correlation between the shot and receiver lines spacing, our most important finding is that 
the effect of irregularities on shot and receiver point location has the greatest impact on structural seismic attributes and, in consequence, on the reliability of the interpretation of faults and fractures. Our results show that the interpretation of subtle features like fractures based on seismic attributes alone may lead to erroneous results. On the other hand, the irregularity seems to have no significant impact on SNR, or the seismic-to-well tie process. Non-intuitively, within the range of tested parameters, the performed analysis points to the receiver lines as a more important factor controlling seismic data quality rather than shot lines. We link this effect to the higher regularity of the receivers' position along the receiver lines in comparison to the location of the shot points.

The research was financed by the National Center for Research and Development (NCBiR) in the frame of the BlueGas Project (BG1/GAZLUPSEJSM/13) as well as the Department of Fossil Fuels Statutory Works. The seismic attribute analysis was carried out by Monika Korbecka as a part of her MSc project, supervised by Jan Barmuta. The authors acknowledge the use of the SeisSpace ProMax for seismic data processing, the Petrel and OpendTect softwares for seismic data interpretation and the Move software for fracture analysis. The software was provided by the Landmark Schlumberger, dGB Earth Sciences and Petex, respectively. The authors are grateful to the section editor, Jadwiga Jarzyna, and the anonymous reviewers for their comments, which improved the content of this paper significantly.

\section{REFERENCES}

Barmuta J., Hadro P. \& Dzwinel K., 2017. Determination of fracture distribution based on seismic attributes and geomechanical modelling. Acta Mineralogica-Petrographica, 32, 614, 4-5.

Chaouch A. \& Mari J.L., 2006. 3-D Land Seismic Surveys: Definition of Geophysical Parameter. Oil \& Gas Science and Technology - Revue d'IFP Energies nouvelles, 61, 611-630.

Cordsen A., Galbraith M. \& Peirce J., 2000. Planning Land 3-D Seismic Surveys. Society of Exploration Geophysicists. https://doi.org/10.1190/1.9781560801801.

Fusen X., Jinli Y., Bo L., Meng Z., Rong L., Fang L., Hongping X., Xue L., Qinglin L. \& Heesom T., 2014. High-density $3 \mathrm{D}$ point receiver seismic acquisition and processing; a case study from the Sichuan Basin, China. First Break, 32, 1, 81-90.
Golonka J., 2009. Phanerozoic paleoenvironment and paleolithofacies maps: Early Paleozoic. Geologia - Kwartalnik Akademii Górniczo-Hutniczej im. Stanisława Staszica w Krakowie, 35, 4, 589-654.

Hakenberg M. \& Świdrowska J., 2001. Cretaceous basin evolution in the Lublin area along the Teisseyre-Tornquist Zone (SE Poland). Annales Societatis Geologorum Poloniae, 71, 1, 1-20.

Kotański Z. \& Buła Z., 1997. Atlas geologiczny Polski: mapy geologiczne ścięcia poziomego: 1:750 000. Wydawnictwa Kartograficzne Polskiej Agencji Ekologicznej, Warszawa.

Krzywiec P., 2009. Devonian-Cretaceous repeated subsidence and uplift along the Teisseyre-Tornquist zone in SE Poland - Insight from seismic data interpretation. Tectonophysics, 475, 1, 142-159.

Krzywiec P., Mazur S., Gągała Ł., Kufrasa M., Lewandowski M., Malinowski M. \& Buffenmyer V., 2017. Late Carboniferous thin-skinned compressional deformation above the SW edge of the East European craton as revealed by seismic reflection and potential field data: Correlations with the Variscides and the Appalachians. [in:] Law R.D., Thigpen J.R., Merschat A.J. \& Stowell H.H. (eds.), Linkages and Feedbacks in Orogenic Systems, GSA Memoir, 213, Geological Society of America, Boulder, 353-372.

Kufrasa M., Słonka Ł., Krzywiec P., Dzwinel K. \& Zacharski J., 2018. Fracture pattern of the Lower Paleozoic sedimentary cover in the Lublin Basin of southeastern Poland derived from seismic attribute analysis and structural restoration. Interpretation, 6, 3, SH73-SH89.

Meunier J. \& Bianchi T., 2005. Cost effective, high density vibroseis acquisition. SEG Technical Program Expanded Abstracts 2005, 44-47. https://doi.org/10.1190/1.2142239.

Meunier J., Bianchi T., Postel J. \& Taylor R., 2008. The future of vibroseis for high-density wide-azimuth land acquisition. First Break, 26, 2, 87-91.

Narkiewicz M., 2010. Development and inversion of Devonian and Carboniferous basins in the eastern part of the Variscan foreland (Poland). Geological Quaterly, 51, 231-256.

Ourabah A., Keggin J., Brooks C., Ellis D. \& Etgen J., 2015. Seismic acquisition, what really matters? SEG Technical Program Expanded Abstracts 2015, 6-11. https://doi. org/10.1190/segam2015-5844787.1.

Pedersen S.I., Randen T., Sonneland L. \& Steen Ø., 2002. Automatic fault extraction using artificial ants. SEG Technical Program Expanded Abstracts 2002, 512-515. https://doi.org/10.1190/1.1817297.

Poprawa P., 2006. Neoproterozoiczny rozpad superkontynentu Rodinii/Pannotii - Zapis w rozwoju basenów osadowych na zachodnim skłonie Baltiki. Prace - Państwowy Instytut Geologiczny, 186, 165-188.

Porębski S.J., Prugar W. \& Zacharski J., 2013. Silurian shales of the East European Platform in Poland - some exploration problems. Przegląd Geologiczny, 61, 11/1, 630-638.

Seeni S.R., Robinson S., Denis M., Sauzedde P. \& Taylor R., 2010. Future-proof seismic: high-density full-azimuth. First Break, 28, 6, 79-88. https://doi.org/0.3997/13652397.28.6.40607. 
Tomaszczyk M. \& Jarosiński M., 2017. The Kock Fault Zone as an indicator of tectonic stress regime changes at the margin of the East European Craton (Poland). Geological Quarterly, 61, 908-925.

Waksmundzka M.I., 2010. Sequence stratigraphy of Carboniferous paralic deposits in the Lublin Basin (SE Poland). Acta Geologica Polonica, 60, 4, 557-597.

Wang X., 2015. Full-Azimuth, High-Density, 3D Single-Point Seismic Survey for Shale Gas Exploration in a Loess Plateau Area, Southeast of Ordos Basin, China. Energy Exploration \& Exploitation, 33, 339-361. https:// doi.org/10.1260/0144-5987.33.3.339.
White R.E., 1973. The estimation of signal spectra and related quantities by means of the multiple coherence function. Geophysical Prospecting, 21, 4, 660-703.

Xiao F., Yang J., Liang B., Zhang M., Li R., Li F., Xiao H., Lei X. \& Liu Q., 2014. Full azimuth high density point source and receiver acquisition helps better characterize geological details in a tight sand reservoir and carbonate reservoir in Sichuan Basin. [in:] Beijing 2014 International Geophysical Conference \& Exposition, Beijing, China, 21-24 April 2014, Society of Exploration Geophysicists and Chinese Petroleum Society, 195-199. https://doi. org/10.1190/IGCBeijing2014-051. 